\title{
Positive perceptions of electronic cigarettes relative to combustible cigarettes are associated with weaker support for endgame policies on combustible cigarettes: A population- based cross-sectional study in Hong Kong
}

\author{
Yongda S. Wu', Man Ping Wang', Sai Yin Ho', Yee Tak Cheung ${ }^{1}$, Antonio Kwong ${ }^{3}$, Vienna Lai ${ }^{3}$, Tai Hing Lam²
}

\begin{abstract}
INTRODuction Positive perceptions of electronic cigarettes (e-cigarettes) relative to combustible cigarettes (CCs) may erode support for endgame policies on CCs through smoking renormalization (increasing public acceptance of smoking). We investigated the associations between perceptions of e-cigarettes relative to CCs and support for endgame policies on CCs in Hong Kong.

METHODS Adult respondents ( $\mathrm{N}=2004)$ were surveyed using landline random digit dialing in 2015. Perceived relative harm and relative addictiveness of e-cigarettes were combined as an overall perception of e-cigarettes relative to CGs with 5 levels and we analyzed individually 'neutral/positive/mixed/unknown' perceptions against the 'negative' perception. Five individual items with dichotomous responses assessed the support for endgame policies on CCs. Support for banning the sale/use of CCs (yes/no) was also assessed. Multivariable regressions yielded adjusted odds ratios (AORs) of supporting endgame policies (individual policy items, all 5 policy items, at least 1 policy item, banning the sale/use of CCs) in relation to perceptions of e-cigarettes relative to CCs, adjusting for age, education attainment, marital status, CG smoking status and ever e-cigarette use.

RESULTS Support for individual endgame policy items (from $51.8 \%$ to $80.0 \%$ ), banning the sale $(63.8 \%)$ and use $(67.5 \%)$ of CCs were generally high. Few respondents perceived e-cigarettes as more harmful $(16.6 \%)$ or more addictive (9.3\%) than CGs. Positive perceptions of e-cigarettes (24.0\%) were associated with less support for 'ban CC sales in 10 years if there is a product providing nicotine not made from tobacco' (AOR=0.62, 95\% CI: 0.40-0.97), 'ban CC use when it's prevalence falls below 5\%' (AOR=0.66, 95\% CI: 0.44-0.98) and 'banning the sale of CCs' (AOR=0.63, 95\% CI: 0.42-0.94).

CONCLUSIONS Positive perceptions of e-cigarettes relative to CCs were associated with less support for endgame policies on CCs in Hong Kong. Public health actions are needed to disseminate evidence-based knowledge of e-cigarettes.
\end{abstract}

\section{AFFILIATION \\ 1 School of Nursing, The University of Hong Kong, Pokfulam, Hong Kong 2 School of Public Health, The University of Hong Kong, Pokfulam, Hong Kong \\ 3 Hong Kong Council on Smoking and Health, Wan \\ Chai, Hong Kong \\ CORRESPONDENCE TO Man Ping Wang. School of Nursing, The University of Hong Kong, 4/F, William M.W. Mong Block, 21 Sassoon Road, Pokfulam, Hong Kong. E-mail: mpwang@hku.hk \\ ORCID ID: https://orcid. org/0000-0003-4000-2388 \\ KEYWORDS \\ electronic cigarettes, tobacco endgame, policy, smoking renormalization}

Received: 12 March 2019 Revised: 8 July 2019 Accepted: 13 July 2019

\section{INTRODUCTION}

Electronic cigarettes (e-cigarettes) are increasingly popular in Hong Kong, US and European countries ${ }^{1-3}$ due to massive advertising and promotion ${ }^{2-4}$. Many e-cigarette promotions claim that these products are free from toxins and less addictive than combustible cigarettes (CCs) ${ }^{5}$. Such promotions of e-cigarettes ignore the fact that an increasing number of studies have found respiratory toxicants, irritants and similar levels of nicotine in aerosols 
from e-cigarettes compared to $\mathrm{CCs}^{6-9}$. E-cigarette promotions with health claims have been linked to positive perceptions of e-cigarettes ${ }^{10}$, which has led to less support for restrictions on e-cigarettes, e.g. use and advertising ${ }^{11,12}$. Public support is crucial for the implementation and enforcement of tobacco control (TC) policies ${ }^{13}$ including those on e-cigarettes.

E-cigarette regulations in Hong Kong are less stringent than for CCs. Although use of e-cigarettes in smoke-free areas is prohibited, only those with nicotine need to be registered as a pharmaceutical product and obtain permission for sale (none has done so as of February 2019), and nicotine-free e-cigarettes are under no other specific regulation. Most of the e-cigarettes in Hong Kong claim to be nicotinefree and can be marketed freely in retail stores and online, and are often promoted as a healthier tobacco product $^{14}$. Over $80 \%$ of the Hong Kong population is aware of e-cigarettes ${ }^{15}$, nearly one-third perceives e-cigarettes as less harmful than CGs and such perceptions are associated with reduced support for e-cigarette regulations ${ }^{16}$.

Positive perceptions of e-cigarettes may renormalize smoking, i.e. e-cigarettes may increase the attractiveness of smoking ${ }^{17}$. If e-cigarettes are portrayed as a healthier tobacco product this might translate to the personal experience and public performance of using $\mathrm{CCs}^{17,18}$. Smoking has become less acceptable to the public as control policies (e.g. increased smoke-free areas) become more stringent and the harms of CCs (the predominantly used tobacco product) are more well known ${ }^{19}$. Effective dissemination of the harms of CC use increases public support for more stringent control policies ${ }^{20}$. In contrast, increasing e-cigarette use and promotions may increase public acceptance of smoking, which in turn may erode support for further control policies on CCs (e.g. endgame policies on CC use). Studies on this renormalization hypothesis are few and have focused on whether e-cigarette use leads to initiation of CG use in youth ${ }^{21}$. A recent Surgeon General's report ${ }^{22}$ and a meta-analysis ${ }^{23}$ concluded that e-cigarette use was associated with the uptake of CCs. No study has investigated the effect of renormalization by e-cigarettes on control policies towards CCs.

Endgame policy is a unique type of TC policy that refers to an end to tobacco use. But consensus on the implementation of endgame is lacking and various approaches have been proposed ${ }^{24,25}$. In Hong Kong, tobacco endgame is generally referred to as the elimination of CC use since combustible cigarettes are the predominantly used tobacco products at present ${ }^{26}$. Over $70 \%$ of respondents in a 2012 population-based survey supported banning tobacco sale, possession or use ${ }^{27}$. Local tobacco advocates have urged the government to strengthen TC policies towards a CC smoking prevalence of $5 \%$ or lower in 2027 and to end CC use and sale ${ }^{28}$.

The relation between positive perceptions of e-cigarettes and public support for control policies on CCs remains unclear. We investigated the crosssectional association of perceptions of e-cigarettes with support for tobacco endgame policies on CC use in a population-based survey.

\section{METHODS}

\section{Study design}

We analyzed data from the Tobacco Control Policyrelated Survey 2015, funded by the Hong Kong Council on Smoking and Health ( $\mathrm{COSH})$ with the consultancy of the Schools of Nursing and Public Health, University of Hong Kong. The fieldwork was conducted by the Public Opinion Program, University of Hong Kong, a well-known local survey agency. Details of the survey have been published elsewhere ${ }^{16}$. In brief, 5252 Chinese speaking respondents from Hong Kong, aged 15 years or older were interviewed, including 1706 current CG users (current smokers, consumed at least $1 \mathrm{CC}$ in the past 7 days), 1712 past CC users (ex-smokers), and 1834 never smokers, with a response rate of $17.8 \%$ (over 6071 eligible cases and 23497 cases whose survey was rescheduled but not done within the survey period). They were sampled through a two-stage landline random digit dialing. The sampling telephone number list was based on a residential telephone directory. Adding 1 or 2 to, or subtracting 1 or 2 from the last digit of the telephone numbers from the directory allowed the inclusion of unlisted numbers. One respondent was selected, using the 'nearest birthday' method, from eligible family members in a successfully contacted household. Current smokers and ex-smokers were over-sampled to obtain reliable estimates since their prevalence was low in Hong Kong ( $10.5 \%$ for current smokers and 5.6\% for ex-smokers in 2015) $)^{26}$. To collect respondents' opinions on various tobacco 
control policies and avoid a lengthy questionnaire that might have jeopardized data quality, a random subsample of respondents was selected to obtain opinions on endgame policies for CCs. Among the 4517 (of 5252 ) respondents who were aware of e-cigarettes and reported their perceptions of e-cigarettes, 2004 respondents who also reported their opinion of endgame policies on CCs were included in this study. Ethical approval of the survey was granted by the Institutional Review Board of the University of Hong Kong/Hospital Authority Hong Kong West Cluster (Ref: UW15-108). All methods were performed in accordance with the relevant guidelines and regulations. All respondents gave informed consent before the survey started.

\section{Measurements}

Perceived relative harm of e-cigarettes (vs CCs) was assessed with 6 response items: 'much more harmful', 'slightly more harmful', 'similar', 'slightly less harmful', 'much less harmful', and 'I don't know'. The responses were combined into 4 categories ('more/ slightly more harmful', 'similarly harmful', 'less/ slightly less harmful', and 'I don't know') for analysis due to a small number of observations in some of the responses. Perceived relative addictiveness of e-cigarettes (vs CGs) was asked with 5 slightly different responses ('more addictive', 'similar', 'less addictive', and 'not addictive', and 'I don't know') given that e-liquids could be free of nicotine. The 'less addictive' and 'not addictive' responses were also combined for analysis. We classified overall perceptions of e-cigarettes relative to CCs based on the perceived relative harm and addictiveness of e-cigarettes (Table 1). The 'Neutral' perception was both 'similar' responses to the questions on harm

Table 1. Categorization of perceptions* of e-cigarettes relative to combustible cigarettes for analysis

\begin{tabular}{l|c|c|c|c|}
\hline $\begin{array}{l}\text { Perceive } \\
\text { relative harm } \\
\text { of e cigarettes }\end{array}$ & \multicolumn{3}{|c|}{ Perceive relative addictiveness of } \\
\cline { 2 - 5 } & Vore & Simigaretices & Less & Don't know \\
\hline More & Negative & Negative & Mixed & Mixed \\
Similar & Negative & Neutral & Positive & Mixed \\
Less & Mixed & Positive & Positive & Mixed \\
\hline Don't know & Mixed & Mixed & Mixed & Unknown \\
\hline
\end{tabular}

*In a representative sample $(\mathrm{N}=2004)$ of the Hong Kong adult population in 2015. and addictiveness relative to CCs, and the 'Unknown' perception was both 'I don't know' responses. The 'Negative' perception included the following types of responses: both 'more harmful' and 'more addictive', 'more harmful' and 'similar addictiveness', and 'similar harm' and 'more addictive'. The 'Positive' perception was defined in a similar manner (both 'less harmful' and 'less addictive', 'less harmful' and 'similar addictiveness', and 'similar harm' and 'less addictive'). Other combinations of responses were grouped into 'Mixed' perception of e-cigarettes relative to CGs.

This study included 5 individual endgame policy items on CCs with dichotomous responses (yes/ no): 'ban CC sales in 10 years if there is a product providing nicotine not made from tobacco', 'ban people who are born after the year 2010 from smoking CGs', 'license to purchase CCs and to smoke', 'set a quota for CC retail and reduce it on a yearly basis', and 'ban CC use when its prevalence falls below $5 \%$ '. These items were analyzed as supporting all 5 policies, at least 1 policy as well as individual policies. 'Refuse' and 'I don't know' responses to individual endgame policy items were excluded in respective analyses since they were few (ranging from $4.1 \%$ to $10.4 \%)$. Another 2 questions assessed support for 2 broad endgame policies on CGs: 'Do you support completely banning the sale of CGs', and 'Do you support completely banning the use of CCs'. Both questions were asked with 7 'support' responses with different deadlines (immediately, in 1 year, in 3 years, in 5 years, in 10 years, after 10 years, deadline not yet determined) and 6 'against' responses with different reasons (people have a right to smoke, negative effect on the economy, ban is useless, increase CC smuggling, being a smoker, others). 'Support' and 'against' responses were combined respectively for analysis. Ever use of e-cigarettes was inquired and users were further asked usage in the past 30 days. But we only used the information on ever use due to the very few respondents with use in the 30 days. Respondents' sociodemographic characteristics were also collected.

\section{Statistical analysis}

Sociodemographic characteristics, perceptions of e-cigarettes relative to CCs and support for endgame policies on CCs were weighted by age, sex, and CC smoking status distributions of the general population 
in Hong Kong in $2015^{26}$. Multivariable logistic regressions yielded adjusted odds ratios (AORs) of support for the endgame policies on CGs (individual policy items, all policy items, and at least 1 policy item) in relation to perceptions of e-cigarettes relative to CGs, adjusting for age, education attainment, marital status, CC smoking status and ever e-cigarette use. Marital status was adjusted because married people were more likely to be concerned about the harms to their partners or children caused by smoking, which in turn may affect their perceptions of e-cigarettes and/or support for endgame policies on combustible cigarettes ${ }^{29,30}$. The relations between perceptions of e-cigarettes relative to CCs and support for 2 broad endgame policies were examined with a similar method to check the robustness of results of individual endgame policy items. As the associations might differ by CC smoking status, effect modification (ex-smokers, current smokers vs never smokers) was tested by adding product terms (perceptions of e-cigarettes relative to CCs $\times$ CC smoking status) in the model and checked by likelihood ratio test comparing models with or without the product terms. All analyses were conducted using Stata (Version 15.1, TX: StataCorp LP, College Station, TX, USA).

\section{RESULTS}

Respondents reporting their support for endgame policies on CCs and those not included in the analysis shared similar sociodemographic characteristics, except that fewer included respondents had a monthly household income of HK $\$ 30000$ or above $(1 \mathrm{US} \$=7.8 \mathrm{HK} \$)(24.6 \%$ vs $27.8 \%, \mathrm{p}=0.04$, data not shown in tables). Over half of the respondents $(52.2 \%)$ were female, and two-thirds $(66.7 \%)$ were aged 30-39 years (Table 2). Ever e-cigarette use was

Table 2. Respondents' sociodemographics, use of e-cigarettes and their associations with perceptions of e cigarettes relative to combustible cigarettes (CCs) $(\mathrm{N}=2004)$

\begin{tabular}{|c|c|c|c|c|c|c|c|}
\hline & \multirow{2}{*}{$\begin{array}{c}\text { AII } \\
\text { respondents } \\
(\%)\end{array}$} & \multicolumn{6}{|c|}{ Perceptions of e cigarettes relative to CCs (\%) } \\
\hline & & Vegalive & Veutral & Posilive & Vlived & Unknown & $p^{*}$ \\
\hline Female & 52.2 & 39.3 & 57.1 & 56.4 & 49.7 & 54.8 & 0.066 \\
\hline Age (years) & & & & & & & $<0.001$ \\
\hline $15-29$ & 23.1 & 27.9 & 20.0 & 35.5 & 22.5 & 5.9 & \\
\hline $30-39$ & 66.7 & 64.5 & 71.6 & 57.3 & 66.4 & 78.4 & \\
\hline$\geq 40$ & 10.2 & 7.7 & 8.5 & 7.2 & 11.1 & 15.7 & \\
\hline Highest educational attainment & & & & & & & 0.001 \\
\hline Primary or below & 7.1 & 5.6 & 4.6 & 4.5 & 7.4 & 13.5 & \\
\hline Secondary & 47.3 & 52.0 & 37.5 & 48.9 & 46.5 & 52.3 & \\
\hline Tertiary or above & 45.7 & 42.4 & 57.9 & 46.6 & 46.2 & 34.2 & \\
\hline Marital status & & & & & & & $<0.001$ \\
\hline Single & 32.9 & 36.3 & 33.1 & 45.2 & 30.7 & 16.9 & \\
\hline Married or cohabited & 62.6 & 56.3 & 64.4 & 51.1 & 64.8 & 77.4 & \\
\hline Divorced or widowed & 4.5 & 7.4 & 2.5 & 3.6 & 4.4 & 5.7 & \\
\hline Monthly household income (HK\$) & & & & & & & 0.110 \\
\hline less than 10000 & 9.0 & 6.9 & 5.1 & 10.3 & 9.2 & 11.6 & \\
\hline 10000-19999 & 13.5 & 12.7 & 13.3 & 14.1 & 12.0 & 17.3 & \\
\hline 20000-29999 & 18.1 & 25.1 & 8.8 & 20.0 & 19.1 & 17.0 & \\
\hline$\geq 30000$ & 59.4 & 55.3 & 72.8 & 55.5 & 59.8 & 54.0 & \\
\hline Combustible cigarette (CC) use status & & & & & & & $<0.001$ \\
\hline Never smokers & 83.9 & 82.6 & 88.6 & 87.9 & 81.6 & 79.5 & \\
\hline Ex-smokers & 4.7 & 3.5 & 4.1 & 3.6 & 5.3 & 6.2 & \\
\hline Current smokers & 11.5 & 13.9 & 7.3 & 8.5 & 13.1 & 14.3 & \\
\hline Ever e-cigarette use & 1.1 & 1.4 & 0.0 & 1.2 & 1.7 & 0.1 & 0.050 \\
\hline
\end{tabular}

All analyses were weighted by age, sex, and CC smoking status distribution of the Hong Kong population in 2015. *Based on chi-squared test. 
Table 3. Perceptions of e-cigarettes relative to combustible cigarettes (CCs) and support for endgame policies on CCs $(\mathrm{N}=2004)$

\begin{tabular}{|c|c|}
\hline \multicolumn{2}{|l|}{ Perceptions of e-cigarettes relative to $\mathrm{CCs}$} \\
\hline \multicolumn{2}{|l|}{ Perceived relative harm of e-cigarettes } \\
\hline More harmful/slightly more harmful & 16.6 \\
\hline Similarly harmful & 22.7 \\
\hline Less harmful/slightly less harmful & 35.4 \\
\hline Don't know & 25.4 \\
\hline \multicolumn{2}{|l|}{ Perceived relative addictiveness of e-cigarettes } \\
\hline More addictive & 13.8 \\
\hline Similarly addictive & 33.4 \\
\hline Less addictive/not addictive & 25.1 \\
\hline Don't know & 27.7 \\
\hline \multicolumn{2}{|l|}{ Overall perceptions of e-cigarettes relative to CCs } \\
\hline Negative (more harmful/addictive) & 9.5 \\
\hline Neutral (similarly harmful/addictive) & 14.0 \\
\hline Positive (less harmful/addictive) & 24.0 \\
\hline Mixed perceptions & 36.6 \\
\hline Unknown (do not know both harm and addictiveness) & 15.9 \\
\hline \multicolumn{2}{|l|}{ Support for endgame policies on CCs } \\
\hline $\begin{array}{l}\text { Ban CC sale in } 10 \text { years if there is a product providing } \\
\text { nicotine not made from tobacco }\end{array}$ & 70.5 \\
\hline $\begin{array}{l}\text { Ban people who are born after the year } 2010 \text { from } \\
\text { smoking CCs }\end{array}$ & 51.8 \\
\hline License to purchase CCs and to smoke & 54.1 \\
\hline Set a quota for $\mathrm{CC}$ retail and reduce it on a yearly basis & 80.0 \\
\hline Ban CC use when its prevalence falls below 5\% & 62.1 \\
\hline All policies & 29.5 \\
\hline At least 1 policy & 88.3 \\
\hline Banning the sale of CCs & 63.8 \\
\hline Banning the use of CCs & 67.5 \\
\hline
\end{tabular}

All analyses were weighted by age, sex, and CC smoking status distribution of the Hong Kong population in 2015 rare $(1.1 \%)$ and $11.5 \%$ of respondents were current CC users. Age, highest educational attainment, marital status, CG use and ever e-cigarette use were associated with perceptions of e-cigarettes (all $\mathrm{p} \leq 0.05)$ and adjusted in logistic regressions.

Few respondents perceived e-cigarettes as more harmful $(16.6 \%)$ or more addictive $(9.3 \%)$ than CGs and about a quarter did not know the relative harm (25.4\%) and addictiveness $(27.7 \%)$ of e-cigarettes (Table 3 ). Only $9.5 \%$ held overall negative perceptions of e-cigarettes relative to CCs, while $24.0 \%$ held positive perceptions and $36.6 \%$ held mixed perceptions. Respondents' support for individual endgame policy items on CCs was generally high (from $51.8 \%$ to $80.0 \%$ ). Over one-quarter of the respondents $(29.5 \%)$ supported all 5 individual policy items and $88.3 \%$ supported at least 1 policy item. Respondents' support for broad endgame policies on CCs was also high: $63.8 \%$ for banning the sale of CCs, and $67.5 \%$ for banning the use of CCs.

Table 4 shows that positive perceptions of e-cigarettes relative to CGs are associated with less support for 'ban CC sales in 10 years if there is a product providing nicotine not made from tobacco' (AOR=0.62, 95\% CI: 0.40-0.97), 'ban CC use when it's prevalence falls below 5\%' (AOR $=0.66,95 \% \mathrm{CI}$ : 0.44-0.98) and 'banning the sale of CCs' $(\mathrm{AOR}=0.63$, 95\% CI: 0.42-0.94). A marginally significant association with 'ban people who are born after the year 2010 from smoking CCs' (AOR=0.71, 95\% CI: 0.49-1.05, p=0.08) was also observed. 'Unknown' perceptions were associated with less support for each of the 5 individual policy items, all 5 policy items, at least 1 policy item and 'banning the sale of CCs' (all

Table 4. Association of perceptions of e-cigarettes relative to combustible cigarettes (CCS) with support for endgame policies on CCs $(\mathrm{N}=2004)$

\begin{tabular}{|c|c|c|c|c|c|c|c|c|}
\hline \multirow{3}{*}{$\begin{array}{l}\text { Support for } \\
\text { endgame } \\
\text { policies on CCs }\end{array}$} & \multicolumn{8}{|c|}{ Perceptions of e cigarettes relative to CCs (positive neutral mixed unknown vs negative) } \\
\hline & \multicolumn{4}{|c|}{ Crude OR $\left(95^{\circ} \% \mathrm{CI}\right)$} & \multicolumn{4}{|c|}{ Adjusted OR $\left(95^{\circ} \circ \mathrm{CI}\right)^{\mathrm{a}}$} \\
\hline & Neutral & Positive & Vised & Unknown & Veutral & Positive & Vived & Unknown \\
\hline $\begin{array}{l}\text { Ban CC sale in } 10 \\
\text { years if there is a } \\
\text { product providing } \\
\text { nicotine not made } \\
\text { from tobacco }\end{array}$ & $\begin{array}{c}0.57 \\
(0.36-0.90)^{*}\end{array}$ & $\begin{array}{c}0.63 \\
(0.41-0.96)^{*}\end{array}$ & $\begin{array}{c}0.59 \\
(0.40-0.88)^{* *}\end{array}$ & $\begin{array}{c}0.49 \\
(0.32-0.74)^{* * *}\end{array}$ & $\begin{array}{c}0.55 \\
(0.34-0.89)^{*}\end{array}$ & $\begin{array}{c}0.62 \\
(0.40-0.97)^{*}\end{array}$ & $\begin{array}{c}0.56 \\
(0.37-0.84)^{* *}\end{array}$ & $\begin{array}{c}0.43 \\
(0.28-0.67)^{* * *}\end{array}$ \\
\hline $\begin{array}{l}\text { Ban people who } \\
\text { are born after the }\end{array}$ & $\begin{array}{c}0.71 \\
(0.47-1.07)^{+}\end{array}$ & $\begin{array}{c}0.71 \\
(0.49-1.02)^{+}\end{array}$ & $\begin{array}{c}0.81 \\
(0.58-1.13)\end{array}$ & $\begin{array}{c}0.70 \\
(0.48-1.00)^{*}\end{array}$ & $\begin{array}{c}0.69 \\
(0.45-1.05)^{+}\end{array}$ & $\begin{array}{c}0.71 \\
(0.49-1.05)^{+}\end{array}$ & $\begin{array}{c}0.78 \\
(0.55-1.10)\end{array}$ & $\begin{array}{c}0.60 \\
(0.41-0.88)^{* *}\end{array}$ \\
\hline
\end{tabular}

year 2010 from

smoking CCs 
Table 4. Continued

\begin{tabular}{|c|c|c|c|c|c|c|c|c|}
\hline \multirow{3}{*}{$\begin{array}{l}\text { Support for } \\
\text { endgame } \\
\text { policies on CCs }\end{array}$} & \multicolumn{8}{|c|}{ Perceptions of e cigarettes relative to CCs (positive neutral mixed unknown vs negative) } \\
\hline & \multicolumn{4}{|c|}{ Crude OR $\left(95^{\circ} \% \mathrm{CI}\right)$} & \multicolumn{4}{|c|}{ Adjusted OR $\left(95^{\circ} \% \mathrm{CI}\right)^{\mathrm{a}}$} \\
\hline & Veutral & Posilive & Vived & Unknown & Veutral & Posilive & Vived & Unknown \\
\hline $\begin{array}{l}\text { License to } \\
\text { purchase CCs } \\
\text { and to smoke }\end{array}$ & $\begin{array}{c}0.85 \\
(0.57-1.26)\end{array}$ & $\begin{array}{c}0.95 \\
(0.66-1.36)\end{array}$ & $\begin{array}{c}0.85 \\
(0.61-1.19)\end{array}$ & $\begin{array}{c}0.58 \\
(0.40-0.82)^{* *}\end{array}$ & $\begin{array}{c}0.78 \\
(0.51-1.19)\end{array}$ & $\begin{array}{c}0.90 \\
(0.61-1.32)\end{array}$ & $\begin{array}{c}0.85 \\
(0.60-1.20)\end{array}$ & $\begin{array}{c}0.54 \\
(0.37-0.79)^{* *}\end{array}$ \\
\hline $\begin{array}{l}\text { Set a quota for } \\
\text { CC retail and } \\
\text { reduce it on a } \\
\text { yearly basis }\end{array}$ & $\begin{array}{c}1.12 \\
(0.71-1.77)\end{array}$ & $\begin{array}{c}1.03 \\
(0.68-1.55)\end{array}$ & $\begin{array}{c}0.94 \\
(0.64-1.37)\end{array}$ & $\begin{array}{c}0.59 \\
(0.40-0.88)^{* *}\end{array}$ & $\begin{array}{c}0.98 \\
(0.59-1.60)\end{array}$ & $\begin{array}{c}0.90 \\
(0.57-1.41)\end{array}$ & $\begin{array}{c}0.92 \\
(0.51-1.38)\end{array}$ & $\begin{array}{c}0.57 \\
(0.37-0.88)^{*}\end{array}$ \\
\hline $\begin{array}{l}\text { Ban CC use when } \\
\text { its prevalence } \\
\text { falls below } 5 \%\end{array}$ & $\begin{array}{c}0.80 \\
(0.53-1.22)\end{array}$ & $\begin{array}{c}0.66 \\
(0.45-0.96)^{*}\end{array}$ & $\begin{array}{c}0.81 \\
(0.57-1.16)\end{array}$ & $\begin{array}{c}0.52 \\
(0.36-0.75)^{* * *}\end{array}$ & $\begin{array}{c}0.77 \\
(0.50-1.21)\end{array}$ & $\begin{array}{c}0.66 \\
(0.44-0.98)^{*}\end{array}$ & $\begin{array}{c}0.78 \\
(0.54-1.13)\end{array}$ & $\begin{array}{c}0.42 \\
(0.28-0.63)^{* * *}\end{array}$ \\
\hline All 5 policy items & $\begin{array}{c}0.89 \\
(0.58-1.37)\end{array}$ & $\begin{array}{c}0.86 \\
(0.58-1.28)\end{array}$ & $\begin{array}{c}0.83 \\
(0.58-1.18)\end{array}$ & $\begin{array}{c}0.67 \\
(0.46-1.00)^{*}\end{array}$ & $\begin{array}{c}0.87 \\
(0.56-1.37)\end{array}$ & $\begin{array}{c}0.83 \\
(0.55-1.24)\end{array}$ & $\begin{array}{c}0.81 \\
(0.55-1.17)\end{array}$ & $\begin{array}{c}0.61 \\
(0.40-0.92)^{*}\end{array}$ \\
\hline $\begin{array}{l}\text { At least } 1 \text { policy } \\
\text { item }\end{array}$ & $\begin{array}{c}0.81 \\
(0.44-1.47)\end{array}$ & $\begin{array}{c}0.77 \\
(0.44-1.33)\end{array}$ & $\begin{array}{c}0.78 \\
(0.47-1.29)\end{array}$ & $\begin{array}{c}0.43 \\
(0.26-0.73)^{* *}\end{array}$ & $\begin{array}{c}0.74 \\
(0.40-1.37)\end{array}$ & $\begin{array}{c}0.76 \\
(0.43-1.34)\end{array}$ & $\begin{array}{c}0.76 \\
(0.45-1.29)\end{array}$ & $\begin{array}{c}0.40 \\
(0.23-0.68)^{* * *}\end{array}$ \\
\hline $\begin{array}{l}\text { Banning the sale } \\
\text { of CCs }\end{array}$ & $\begin{array}{c}0.77 \\
(0.51-1.17)\end{array}$ & $\begin{array}{c}0.63 \\
(0.43-0.92)^{*}\end{array}$ & $\begin{array}{c}0.75 \\
(0.53-1.07)\end{array}$ & $\begin{array}{c}0.72 \\
(0.49-1.05)^{+}\end{array}$ & $\begin{array}{c}0.72 \\
(0.47-1.12)\end{array}$ & $\begin{array}{c}0.63 \\
(0.42-0.94)^{*}\end{array}$ & $\begin{array}{c}0.72 \\
(0.50-1.04)^{+}\end{array}$ & $\begin{array}{c}0.62 \\
(0.41-0.92)^{*}\end{array}$ \\
\hline $\begin{array}{l}\text { Banning the use } \\
\text { of CCs }\end{array}$ & $\begin{array}{c}1.04 \\
(0.69-1.57)\end{array}$ & $\begin{array}{c}1.00 \\
(0.69-1.46)\end{array}$ & $\begin{array}{c}1.08 \\
(0.77-1.52)\end{array}$ & $\begin{array}{c}0.94 \\
(0.65-1.37)\end{array}$ & $\begin{array}{c}0.96 \\
(0.62-1.49)\end{array}$ & $\begin{array}{c}1.02 \\
(0.68-1.52)\end{array}$ & $\begin{array}{c}1.05 \\
(0.73-1.51)\end{array}$ & $\begin{array}{c}0.81 \\
(0.54-1.20)\end{array}$ \\
\hline
\end{tabular}

a Adjusting for age, highest educational attainment, marital status, ever e-cigarette use and CC smoking status (never smoker, ex-smoker, current smoker). In a representative sample ( $N=2004)$ of the Hong Kong adult population in 2015. $+p<0.1,{ }^{*} p<0.05,{ }^{* *} p<0.01,{ }^{* * *} p<0.001$.

$\mathrm{p}<0.05$ ). Product terms (perceptions of e-cigarettes relative to CCs $\times$ CG smoking status) used to test effect modification were not statistically significant (all $\mathrm{p}>0.05$ ) and this was consistent with results from likelihood ratio tests (all $\mathrm{p}>0.05$, suggesting adding product terms did not significantly improve model fit) (data not shown in tables).

\section{DISCUSSION}

We found positive perceptions of e-cigarettes relative to CCs were associated with less support for endgame policies on CCs. Associations were observed for individual endgame policy items and broad endgame policies, suggesting robustness in the results. These results were similar to those of previous studies, which found that more harmful or more addictive perceptions of e-cigarettes were associated with greater support for e-cigarette regulations on use, sale, and advertising ${ }^{12,16}$, and that perceptions of the negative health effects of smoking CGs were associated with supporting control policies on the use and sale of $\mathrm{CCs}^{20,31}$. Similar to the adult population of the US, only a small proportion (9.5\%) of adults in Hong Kong held negative perceptions of e-cigarettes (perceived e-cigarettes as more harmful or more addictive than CCs) $)^{32}$. Uncommon negative perceptions of e-cigarettes relative to CGs could be partly attributed to massive e-cigarette marketing ${ }^{4}$ that featured harm reduction (such as no tar, no tobacco ${ }^{5,33}$ ). Since promotions of e-cigarettes may foster positive perceptions of the product, our findings suggest massive promotion of e-cigarettes may subsequently obstruct endgame to CCs by shrinking its public support.

Our findings are in favor of the renormalization hypothesis: positive perceptions of e-cigarettes relative to CCs may erode public support for control policies on CGs. One possible mechanism of our findings is that e-cigarettes may alter attitudes towards smoking ${ }^{34}$. E-cigarette use experience and performance closely mimic that of combustible cigarettes, which may empower it to shape a favorable attitude towards smoking in the public given the positive perceptions of e-cigarettes relative to $\mathrm{CCs}^{18}$. Further longitudinal studies and randomized control trials are needed to establish the causal relations between positive perceptions of e-cigarettes relative to CCs and reduced support for control policies on CGs. The underlying mechanism of smoking renormalization hypothesis, which would inform education and counter promotion 
campaigns on e-cigarettes, should also be carefully examined.

Our findings should also be interpreted in the context of 'harm reduction' strategy advocated by the tobacco companies, in which the health consequences of e-cigarettes are overlooked. The level of harm of e-cigarettes varies due to the diversity of products and how they are used, which decide the composition and amount of toxic substances in aerosols emitted ${ }^{6}$. The level of nicotine delivered by e-cigarettes could be similar to that from $\mathrm{CCs}^{6,9}$. Limited short-term evidence precludes the conclusion that e-cigarettes are less harmful and less addictive, let alone have health benefits. 'Harm reduction' claims could be misleading and are likely to be another attempt to sustain a business based on nicotine dependence, which have also been used in promoting 'safer' cigarettes and snus ${ }^{35,36}$.

The public should be informed about the updated scientific evidence on the harm and addictiveness of e-cigarettes and counter-marketing should be considered to counteract misleading messages. More stringent regulations, including bans on promotion, flavors, use in smoke-free areas etc., on e-cigarettes should be considered to minimize the potential for smoking renormalization and to maximize their effectiveness on harm reduction. These stronger regulations on e-cigarettes are widely supported by the public, regardless of CG or e-cigarette smoking status $^{11,16,37,38}$.

\section{Limitations}

This study has several limitations. First, the cross-sectional design precludes drawing causal conclusions. Longitudinal surveys at regular intervals to monitor changes in perceptions of e-cigarettes (absolute and relative to CCs) and support for endgame policies on CCs are needed. Second, the current sample may not represent the general Hong Kong population since those without a landline at home or not covered by our sampling frame could not be included. No information on refused respondents could be collected and thus the effect of potential bias could not be estimated, but the data were weighted to the Hong Kong census data to handle oversampling of current and ex-smokers and the difference in age and gender distribution between the current sample and the underlying population. Third, our results may not be generalizable to other countries where the level of TC regulations and acceptability of smoking are different, but may still shed light on future scenarios for public support for TC when these countries tighten TC policies and reduce CC smoking prevalence.

\section{CONCLUSIONS}

Positive perceptions of e-cigarettes relative to CCs were associated with less support for endgame policies on CCs in adults in Hong Kong. Public health actions are needed to disseminate evidence-based knowledge on e-cigarettes. More stringent regulations on e-cigarette promotions and use should be considered and public knowledge of and attitudes towards e-cigarettes should be continuously monitored.

\section{REFERENCES}

1. King BA, Patel R, Nguyen KH, Dube SR. Trends in Awareness and Use of Electronic Cigarettes Among US Adults, 2010-2013. Nicotine Tob Res. 2015;17:219-227. doi:10.1093/ntr/ntu191

2. Wang MP, Li W, Jiang N, et al. E-Cigarette Awareness, Perceptions and Use among Community-Recruited Smokers in Hong Kong. PLoS One. 2015;10:e0141683. doi:10.1371/journal.pone.0141683

3. Filippidis FT, Laverty AA, Fernandez E, Mons U, Tigova O, Vardavas CI. Correlates of self-reported exposure to advertising of tobacco products and electronic cigarettes across 28 European Union member states. Tob Control. 2017;26:e130-e133. doi:10.1136/tobaccocontrol-2016-053479

4. Kornfield R, Huang J, Vera L, Emery SL. Rapidly increasing promotional expenditures for e-cigarettes. Tob Control. 2015;24:110-111. doi:10.1136/tobaccocontrol-2014-051580

5. Klein EG, Berman M, Hemmerich N, Carlson C, Htut S, Slater M. Online E-cigarette Marketing Claims: A Systematic Content and Legal Analysis. Tob Regul Sci. 2016;2:252-262. doi:10.18001/TRS.2.3.5

6. Committee on the Review of the Health Effects of Electronic Nicotine Delivery Systems, Board on Population Health and Public Health Practice, Health and Medicine Division, National Academies of Sciences, Engineering, and Medicine. Public Health Consequences of E-Cigarettes. Stratton K, Kwan LY, Eaton DL, eds. Washington, DC: National Academies Press; 2018. https://www.nap.edu/catalog/24952. Accessed January $24,2018$.

7. Huang SJ, Xu YM, Lau ATY. Electronic cigarette: A recent update of its toxic effects on humans. J Cell Physiol. 2018;233:4466-4478. doi:10.1002/jcp.26352

8. Goniewicz ML, Smith DM, Edwards KC, et al. 
Comparison of Nicotine and Toxicant Exposure in Users of Electronic Cigarettes and Combustible Cigarettes. JAMA Netw Open. 2018;1:e185937-e185937. doi:10.1001/jamanetworkopen.2018.5937

9. Goniewicz ML, Boykan R, Messina CR, Eliscu A, Tolentino J. High exposure to nicotine among adolescents who use Juul and other vape pod systems ('pods'). Tob Control. 2018. doi:10.1136/tobaccocontrol-2018-054565

10. Pokhrel P, Fagan P, Kehl L, Herzog TA. Receptivity to E-cigarette Marketing, Harm Perceptions, and E-cigarette Use. Am J Health Behav. 2015;39:121-131. doi:10.5993/ajhb.39.1.13

11. Wackowski OA, Delnevo CD. Smokers' attitudes and support for e-cigarette policies and regulation in the USA. Tob Control. 2015;24:543-546. doi:10.1136/tobaccocontrol-2014-051953

12. Brose LS, Partos TR, Hitchman SC, McNeill A. Support for e-cigarette policies: a survey of smokers and exsmokers in Great Britain. Tob Control. 2017;26:e7-e15. doi:10.1136/tobaccocontrol-2016-052987

13. Wilson H, Thomson G. 'Balancing acts': The politics and processes of smokefree area policymaking in a small state. Health Policy. 2011;101:79-86. doi:10.1016/j.healthpol.2010.08.017

14. Tobacco and Alcohol Control Office. Tobacco Control Legislation - Meaning and Regulation on Tobacco Advertisement. https://www.taco.gov.hk/t/english/ legislation/legislation_ta.html. Accessed November 2, 2017.

15. Jiang N, Chen J, Wang MP, et al. Electronic cigarette awareness and use among adults in Hong Kong. Addict Behav. 2016;52:34-38. doi:10.1016/j.addbeh.2015.08.008

16. Cheung YTD, Wang MP, Ho SY, et al. Public Support for Electronic Cigarette Regulation in Hong Kong: A Population-Based Cross-Sectional Study. Int J Environ Res Public Health. 2017;14:709. doi:10.3390/ijerph14070709

17. Fairchild AL, Bayer R, Colgrove J. The renormalization of smoking? E-cigarettes and the tobacco 'endgame.' N Engl J Med. 2014;370:293-295. doi:10.1056/NEJMp1313940

18. WHO Framework Convention on Tobacco Control. Electronic nicotine delivery systems: Report by WHO. FCTC/COP/6/10 Rev.1. Moscow: WHO; 2014. http:// apps.who.int/gb/fctc/PDF/cop6/FCTC_COP6_10Rev1en.pdf?ua=1. Accessed January 24, 2018.

19. Ashley MJ. What the public thinks about the tobacco industry and its products. Tob Control. 2003;12:396-400. doi:10.1136/tc.12.4.396

20. Li Q, Hyland A, O’Connor R, et al. Support for smoke-free policies among smokers and non-smokers in six cities in China: ITC China Survey. Tob Control. 2010;19:i40-i46. doi:10.1136/tc.2009.029850

21. Dutra LM, Glantz SA. E-cigarettes and National Adolescent Cigarette Use: 2004-2014. Pediatrics. 2017;139:e20162450. doi:10.1542/peds.2016-2450
22. Office of the Surgeon General. E-Cigarette Use Among Youth and Young Adults : a report of the Surgeon General. Rockville, MD: U.S. Department of Health and Human Services, Public Health Service; 2016. https:// www.surgeongeneral.gov/library/2016ecigarettes/index. html. Accessed January 31, 2018.

23. Soneji S, Barrington-Trimis JL, Wills TA, et al. Association Between Initial Use of e-Cigarettes and Subsequent Cigarette Smoking Among Adolescents and Young Adults: A Systematic Review and Meta-analysis. JAMA Pediatr. 2017;171:788-797. doi:10.1001/jamapediatrics.2017.1488

24. Malone RE. Tobacco endgames: what they are and are not, issues for tobacco control strategic planning and a possible US scenario. Tob Control. 2013;22:i42-i44. doi:10.1136/tobaccocontrol-2012-050820

25. McDaniel PA, Smith EA, Malone RE. The tobacco endgame: a qualitative review and synthesis. Tob Control. 2016;25:594604. doi:10.1136/tobaccocontrol-2015-052356

26. Census and Statistics Department, Hong Kong Special Administrative Region. Thematic Household Survey Report No. 59. Hong Kong; 2016. https://www.statistics. gov.hk/pub/B11302592016XXXXB0100.pdf. Accessed July 19, 2016.

27. Wang MP, Wang X, Lam TH, Viswanath K, Chan SS. The tobacco endgame in Hong Kong: public support for a total ban on tobacco sales. Tob Control. 2015;24:162-167. doi:10.1136/tobaccocontrol-2013-051092

28. Hong Kong Council on Smoking and Health. Marking the achievements in tobacco control and Taking a leap towards a tobacco endgame in Hong Kong. http://www. smokefree.hk/en/content/web.do?page=news20171201. Published December 1, 2017. Accessed June 11, 2018.

29. Ruokolainen O, Ollila H, Patja K, Borodulin K, Laatikainen $\mathrm{T}$, Korhonen T. Social climate on tobacco control in an advanced tobacco control country: A population-based study in Finland. Nord Stud Alcohol Drugs. 2018;35:152164. doi:10.1177/1455072518767750

30. Broms U, Silventoinen K, Lahelma E, Koskenvuo M, Kaprio J. Smoking cessation by socioeconomic status and marital status: The contribution of smoking behavior and family background. Nicotine Tob Res. 2004;6:447-455. doi:10.1080/14622200410001696637

31. Blake KD, Viswanath K, Blendon RJ, Vallone D. The role of tobacco-specific media exposure, knowledge, and smoking status on selected attitudes toward tobacco control. Nicotine Tob Res. 2010;12:117-126. doi:10.1093/ntr/ntp184

32. Majeed BA, Weaver SR, Gregory KR, et al. Changing Perceptions of Harm of E-Cigarettes Among U.S. Adults, 2012-2015. Am J Prev Med. 2017;52:331-338. doi:10.1016/j.amepre.2016.08.039

33. Yao T, Jiang N, Grana R, Ling PM, Glantz SA. A content analysis of electronic cigarette manufacturer websites in China. Tob Control. 2016;25:188-194. 
doi:10.1136/tobaccocontrol-2014-051840

34. Macy JT, Chassin L, Presson CC. The Association Between Implicit and Explicit Attitudes Toward Smoking and Support for Tobacco Control Measures. Nicotine Tob Res. 2013;15:291-296. doi:10.1093/ntr/nts117

35. Pollay RW, Dewhirst T. The dark side of marketing seemingly 'Light' cigarettes: successful images and failed fact. Tob Control. 2002;11:i18-i31. doi:10.1136/tc.11.suppl_1.i18

36. Tomar SL. Epidemiologic Perspectives on Smokeless Tobacco Marketing and Population Harm. Am J Prev Med. 2007;33:S387-S397. doi:10.1016/j.amepre.2007.09.009

37. Laverty AA, Filippidis FT, Fernandez E, Vardavas CI. E-cigarette use and support for banning e-cigarette use in public places in the European Union. Prev Med. 2017;105:10-14. doi:10.1016/j.ypmed.2017.08.007

38. Unger JB, Barker D, Baezconde-Garbanati L, Soto DW, Sussman S. Support for electronic cigarette regulations among California voters. Tob Control. 2016. doi:10.1136/tobaccocontrol-2016-052918
ACKNOWLEDGEMENTS

We thank the respondents for their support and the Public Opinion Program, University of Hong Kong, for conducting the survey.

\section{CONFLICTS OF INTEREST}

The authors declare that they have no competing interests, financial or otherwise, related to the current work. M.P. Wang reports grants from Hong Kong Council on Smoking and Health, during the conduct of the study. The rest of the authors have also completed and submitted an ICMJE form for disclosure of potential conflicts of interest.

\section{FUNDING}

This work was supported by the Hong Kong Council on Smoking and Health (https://www.smokefree.hk/tc/content/home.do) by funds to MPW. The funding organization had no role in the study design, data collection and analysis, decision to publish, or preparation of the manuscript.

\section{AUTHORS' CONTRIBUTIONS}

M.P.W. had full access to all of the data in the study and takes responsibility for the integrity of the data and the accuracy of the data analysis. Study concept and design: M.P.W., S.Y.H., Y.T.C., A.K., V.L. and T.H.L. Obtained funding: M.P.W., S.Y.H., Y.T.C., and T.H.L.

Survey administration: M.P.W. and Y.T.C. Statistical analysis: Y.S.W. and M.P.W. Drafting of the manuscript: Y.S.W. and M.P.W. Critical revision of the manuscript for important intellectual content and final approval of the manuscript by all the authors.

PROVENANCE AND PEER REVIEW

Not commissioned; externally peer reviewed. 